\title{
REPERCUSSÕES DA EPISIOTOMIA SOBRE A SEXUALIDADE
}

\author{
Episiotomy Repercussion on Sexuality \\ Repercusión de la Episiotomía sobre la Sexualidad
}

Jane Márcia Progianti ${ }^{1}$

Luciane Marques de Araújo²

Ricardo José Oliveira Mouta ${ }^{3}$

\section{Resumo}

0 estudo visa descrever as sensações vivenciadas pelas mulheres durante a realização da episiotomia e analisar as repercussões desta prática sobre sua sexualidade. É de natureza qualitativa e foi realizado com dez mulheres em uma maternidade pública da Secretaria Municipal de Saúde da Cidade do Rio de Janeiro, de setembro a dezembro de 2005. Os dados foram obtidos através da entrevista semi-estruturada, e os depoimentos foram categorizados seguindo as técnicas da análise de conteúdo. As sensações vividas pelas mulheres durante o procedimento estão associadas ao trauma por serem dolorosas, provocadas por agentes externos à sua fisiologia corporal e sem o seu consentimento prévio. A episiotomia afetou a sexualidade das mulheres por interferir em seus partos, em suas relações sexuais e familiares. Concluímos que, por ser a episiotomia uma violação dos direitos sexuais e reprodutivos das mulheres, tornase imprescindível que as enfermeiras realizem a proteção perineal como prática incorporada.

Palavras-chave: Episiotomia. Sexualidade. Saúde da Mulher. Saúde Reprodutiva.

\begin{abstract}
The study aims to describe the sensations lived by women during the accomplishment of episiotomy and also to analyze the repercussions of this practice on their sexuality. It is qualitative study accomplished with ten women in a governmental maternity administrated by the Rio de Janeiro's Municipal Health Office, from September to December 2005. Data were obtained by semi-structured interview and the statements were classified according the content analysis methodology. The sensations lived by the women during the procedure are associated to a trauma for being painful, for being provoked by external agents to their corporal physiology and without their previous consent. The episiotomy affected the women's sexuality for interfering in their childbirths, in their sexual and family relationships. We concluded that, because the episiotomy represents violation of the women's sexual and reproductive rights, it is indispensable that nurses accomplish the perineal protection procedure as one incorporated in their daily practice.
\end{abstract}

Keywords:

Episiotomy. Sexuality. Women's Health. Reproductive Medicine.

\section{Resumen}

El estudio busca describir las sensaciones vividas por las mujeres durante el logro de la episiotomía y también analizar las repercusiones de esta práctica en su sexualidad. Es un estudio cualitativo logrado con diez mujeres en un maternidad gubernamental administrada de por la Oficina Municipal de Salud de Río de Janeiro, de septiembre a diciembre de 2005. Los datos fueron obtenidos por entrevistas semi-estructuradas y las deposiciones fueron clasificadas según la metodología de análisis de contenido. Se asocian las sensaciones vividas por las mujeres durante el procedimiento a un trauma por ser doloroso, por ser provocado por agentes externos a su fisiología corpórea y sin su consentimiento anterior. La episiotomía afectó la sexualidad de las mujeres por interferir en sus partos, en sus relaciones sexuales y familiares. Nosotros concluimos que, porque ser la episiotomía una violación de los derechos sexuales y reproductivos de las mujeres, es indispensable que enfermeras logren el procedimiento de la protección perineal como incorporado en su práctica diaria.

Palabras clave:

Episiotomía. Sexualidad. Salud de las Mujeres. Medicina Reproductiva. 


\section{INTRODUÇÃO}

0 conceito de direitos sexuais e reprodutivos traz à tona os quatro princípios éticos inegociáveis que estes direitos envolvem: a igualdade, a diversidade, a autonomia pessoal ou princípio da pessoalidade, e a integridade corporal. Cada um destes princípios pode ser violado por atos de invasão ou abuso - por governos, médicos, maridos, parceiros ou membros da família - ou resultar da omissão, da negligência e da discriminação $0^{1,2}$.

Assim sendo, o princípio da igualdade se aplica aos direitos sexuais e reprodutivos em dois âmbitos principais: o campo das relações entre homens e mulheres (sistema de gênero); e a esfera das relações entre as próprias mulheres (definida por condições de classe, raça, etnia, nacionalidade). 0 princípio da diversidade exige o respeito pelas diferenças que existem entre as mulheres em termos de valores, cultura, religião, orientação sexual, condiç̃̃es familiares e de saúde ${ }^{1}$.

Neste estudo, buscamos sustentação no princípio de autonomia pessoal, que implica o respeito pela maneira pela qual as mulheres tomam suas decisões reprodutivas, pelos valores que estas decisões explicitam e pelas redes de apoio que foram consultadas no processo, e a noção de integridade corporal ou o direito de segurança e controle sobre o próprio corpo, que constitui, possivelmente, o fundamento mais importante da liberdade sexual e reprodutiva'.

Trouxemos, então, a autonomia pessoal e a integridade corporal para o contexto dos serviços de saúde no intuito de discutir a prática da episiotomia porque entendemos que estes princípios deveriam orientar as ações profissionais no sentido do respeito às mulheres como seres humanos dotados de emoção, discernimento e capacidade de decisão e que as práticas deveriam envolver a concepção de inviolabilidade do corpo.

A sexualidade neste estudo será entendida como toda uma série de excitações e atividades presentes desde a infância que proporcionam prazer irredutível a alguma necessidade fisiológica fundamental e vital (respiração, fome, excreção, parto) e que se encontram presentes como componentes da chamada forma normal do amor sexual. Ela é polimorfa, polivalente, ultrapassa a necessidade fisiológica e tem a ver com a simbolização do desejo. Num contexto mais amplo, considera-se que a influência da sexualidade permeia todas as manifestações humanas, do nascimento até a morte, e tem na genitalidade um de seus aspectos $^{3}$. Desta maneira, o parto deve ser incluído como uma vivência sexual da mulher, pois gera uma série de excitações que poderá lhe proporcionar prazer.

Do ponto de vista da fisiologia, o trabalho de parto, o parto e a fase inicial da amamentação são partes integrais da vida sexual da mulher, pois nestes momentos dois grupos de hormônios estão sempre presentes, ocitocina e as endorfinas. A ocitocina, entre suas outras funções, estimula as contrações uterinas durante o orgasmo, o trabalho de parto e parto, e as endorfinas são responsáveis pelas sensações de recompensa, gratificação e prazer. Acrescenta-se ainda que um meio cultural, ao interferir rotineiramente na fisiologia do parto, o faz também com a sexualidade ${ }^{4,5}$.

A violência contra a mulher foi entendida conceitualmente como parte de um contexto sócio-econômico e cultural que, historicamente, discrimina o sexo feminino. A manutenção dessas discriminações tem como conseqüência um conjunto de situações desvantajosas para as mulheres, que reforçam e são reforçadas por práticas de violência de gênero. A manutenção da mentalidade de que os homens são superiores às mulheres, e de que a "natureza masculina" confere ao homem o poder no espaço público e no espaço privado, está na base cultural que legitima a violência contra a mulher $r^{6,7,8,9}$.

A evolução da ciência e da tecnologia acarretou grandes transformações no modo de nascer e de parir. 0 uso rotineiro da episiotomia começou a ser defendido em 1895, por Stahl, que argumentava que a episiotomia permitia uma melhor restauração do períneo em relação às lacerações perineais. Na prática obstétrica dos Estados Unidos, o auge deste procedimento se deu após 1920, com as publicações sobre 0 assunto dos médicos Pomeroy e De Lee $^{10}$. No Brasil, foi somente a partir dos anos de 1970 que foi incorporada pela prática obstétrica médica e transformou-se num procedimento de rotina nos hospitais.

Deste modo, para muitos médicos e enfermeiras, a episiotomia consiste no alargamento do orifício vaginal por meio de uma incisão perineal, realizada com tesoura ou bisturi, durante o início da expulsão fetal. Esse procedimento requer reparo cirúrgico posterior e tem por objetivo impedir ou minorar o trauma dos tecidos do canal do parto, favorecer a descida e a liberação do feto e evitar lesões na cabeça do concepto ${ }^{11,12}$.

Entretanto, alguns desses profissionais, apesar de não condenarem este procedimento, apresentam críticas através de estudos que apontam algumas desvantagens da utilização habitual da episiotomia, tais como necessidade de reparo cirúrgico, perda sanguínea, custo alto, desconforto materno e alterações na função sexual ${ }^{11}$.

Muitos médicos e enfermeiras obstétricas afirmam que a episiotomia é a única operação feita sobre o corpo de uma mulher saudável sem o seu consentimento. Por esta razão, é um procedimento que viola os direitos sexuais e reprodutivos da mulher e desrespeita os princípios éticos profissionais ${ }^{13,14}$.

Para esses profissionais, esta operação obstétrica, que é a mais freqüentemente realizada no ocidente, representa o poder da obstetrícia masculina, evita que as mulheres vivenciem o parto como evento sexual, além de representar um ritual de mutilação genital que impede a vivência da sexualidade durante o parto e nascimento ${ }^{13}$.

Diante desta problemática, pretendemos com este estudo descrever as sensações vivenciadas pelas mulheres durante a realização da episiotomia e analisar as repercussões desta prática sobre sua sexualidade.

\section{METODOLOGIA}

Este estudo é de natureza qualitativa, pois buscamos informações precisas e detalhadas sobre as características de um grupo em um nível da realidade que não pode ser quantificado ${ }^{15}$.

Para obtenção dos depoimentos, utilizamos como instrumento a entrevista semi-estruturada, com uma questão inicial: Fale-me a respeito do(s) seu(s) parto(s) e pós-parto(s), em especial, sobre a episiotomia. Deste modo, o entrevistador deixava falar a entrevistada, proporcionando-lhe apenas 
algumas orientações, porém, quando ela se desviava do tema original, o entrevistador voltava a centrar a conversação sobre o assunto ${ }^{16}$.

As entrevistas foram realizadas com mulheres que já haviam sido submetidas a episiotomia em algum momento de sua vida. 0 número de depoentes totalizou dez, ocasião em que ocorreu a saturação dos depoimentos. Essas mulheres foram entrevistadas no momento da consulta de pré-natal ou de pósnatal, em uma maternidade pública da Secretaria Municipal de Saúde da Cidade do Rio de Janeiro. A coleta de dados ocorreu de setembro a dezembro de 2005.

A análise dos dados seguiu três etapas da análise de conteúdo: a primeira, denominada pré-análise, tratou da organização do material, tendo como objetivo tornar operacional e sistematizar as idéias iniciais, direcionando o desenvolvimento das operações subseqüentes. A segunda fase consistiu na exploração do material com a codificação, o desconto [recorte], a enumeração [classificação] ou a agregação [categorização; são classificados os elementos constitutivos de um conjunto, agrupando-os de acordo com suas semelhanças]. Na terceira e última etapa, deu-se a interpretação dos resultados obtidos à luz dos conceitos em que o estudo se apoiou ${ }^{17}$.

Atendendo a Resolução 196/96 do Ministério da Saúde ${ }^{18}$, que trata das normas sobre pesquisa envolvendo seres humanos, foi solicitada à direção da instituição utilizada como cenário a permissão para realização da pesquisa. 0 Conselho de Ética em Pesquisa da Secretaria Municipal de Saúde do Rio de Janeiro deu parecer favorável ao projeto protocolado com o número 53A/05. Posteriormente à aprovação, foi solicitada às depoentes, por meio de termo de Consentimento Livre e Esclarecido, a autorização para a gravação da entrevista e utilização dos depoimentos na pesquisa; tendo sido garantido às mesmas o anonimato de seus depoimentos.

\section{ANÁLISE DO DISCURSO}

As entrevistadas encontravam-se na faixa etária de 19 a 46 anos, e o número de filhos variou entre 1 e 4.0 grau de escolaridade predominante foi $02^{\circ}$ grau completo, e apenas uma entrevistada possuía o $3^{\circ} \mathrm{grau}$ completo. As profissões foram diversas, havia desde uma médica até uma estudante. Em relação à situação conjugal, três mulheres eram casadas ou viviam em união estável, e uma estava solteira. 0 tempo decorrido desde a primeira episiotomia variou de 5 a 16 anos.

Durante o processo de análise, encontramos duas grandes categorias: sensação vivida pela mulher durante a realização da episiotomia e as repercussões da episiotomia sobre sua sexualidade.

\section{A sensação vivida pela mulher no momento da realização da episiotomia - o trauma estabelecido}

As sensações vividas pela mulher durante a realização do procedimento foram associadas ao trauma por causarem preocupações, incômodos físicos e dor. Neste sentido, os depoimentos mostraram uma grande preocupação em relação à ocorrência de deformidades na aparência da genitália:

Nas duas [episiotomias] imaginava se estavam me deixando toda larga e se ia ficar feio ou não, se ia ficar bem costurado. (E5)

\section{Imaginava o quanto fiquei larga.(E9)}

Algumas mulheres relataram ter sentido dor e vivido uma sensação de estranheza, além da preocupação de ter ficado larga:

Depois veio a parte pior que eu achei, foi na hora da costura, senti dor e uma sensação estranha na hora que a linha passava, muito estranha. (E9)

Paradoxalmente, em vez de as mulheres relacionarem a ampliação de suas genitálias à saída do bebê, elas relacionaram o "estar larga" com a episiotomia, que muitas vezes foi considerada um estrago, porque as mulheres a dimensionaram em função da contagem do número de pontos (sutura) recebidos e da dor sentida pela falta de anestesia:

Mas o que foi mais difícil para mim foi o momento de dar os pontos. Achava que tinham cortado até o ânus. A sensação que eu tinha era que estava toda aberta, de tanto ponto que me davam. E a anestesia não pegou direito, então eu sentia todos os pontos, um a um, e só imaginava o tamanho do estrago que tinham feito na minha vagina. (E7)

Todos os depoimentos que evidenciaram a vivência da sensação de dor, proveniente da realização da episiotomia, fortalecem a idéia de que este procedimento provoca um trauma. Deste modo, concordamos que trauma seja todo procedimento externo e necessariamente invasivo da fisiologia que pode resultar em uma experiência dolorosa para a mulher, para o bebê e para ambos ${ }^{19}$. Sendo assim, acredita-se que estas sensações de preocupação e de dor, criadas pelo profissional e que foram sentidas pela mulher, poderão trazer conseqüências para sua integridade psíquica e de seu bebê. ${ }^{20}$

\section{Repercussões sobre a sexualidade das mulheres}

Os órgãos genitais são privilegiados na sexualidade adulta, especialmente porque trata-se de parte do corpo cercada de representações e simbolismos ${ }^{3}$. Ao investigarmos as repercussões da episiotomia sobre a sexualidade das mulheres, esta afirmação foi confirmada pelas próprias mulheres que se referiram à sexualidade como sendo exclusivamente a vivência da genitalidade. Chama atenção, também, o fato de que o parto não foi vivido pela mulher como uma das expressões da sexualidade, e sim como um corte, que inclusive interfere negativamente sobre sua "sexualidade":

Foi o meu parto, foi um corte. [...] 0 meu grande receio era esse. Por mais que eu tentasse explicar, na minha cabeça eu achava que ele não ia entender. la achar que era uma coisa nojenta, sei lá, ou ia ter receio de se envolver sexualmente comigo.(E4)

No entanto, ao colocarmos o parto como um evento que faz parte da sexualidade feminina ${ }^{4,5}$, evidenciamos que as mulheres relataram repercussões negativas no momento do parto e no pós-parto, em virtude da dor e dos incômodos físicos que atrapalhavam a liberdade corporal:

Houve a episiorrafia e aí é que eu me dei conta do procedimento, pois doeu bastante, tanto na hora quanto depois, e me incomodava demais para sentar.(E1) 
0 mais incômodo do pós-parto, além da dor do corte local que dificultava sentar... (E2)

Percebemos que todas as excitações que poderiam proporcionar prazer proveniente de um evento fisiológico fundamental e vital, como o parto, ficaram prejudicadas com 0 procedimento, e as mulheres passaram a rejeitar o natural:

Sempre quis que meu parto fosse normal, mas depois do que eu passei por causa desse maldito corte, mudei totalmente o meu pensamento.(E8)

É muito interessante percebermos que, ao invés das mulheres questionarem e rejeitarem o procedimento, elas passam a desejar um procedimento cirúrgico com grandes riscos comprovados - a cesariana, o que mostra uma alteração em seu senso de segurança. A rejeição da mulher ao parto, e não à episiotomia, fortalece a prática médica intervencionista e em nossa opinião é a contribuição das usuárias dos serviços de saúde brasileiros aos altos índices de cesariana do país:

...Só que desta vez foi cesariana, pois não queria outro

filho de parto normal de jeito nenhum.(E10)

Exatamente por esta razão compreendemos que a episiotomia se constitui numa violência contra a mulher, pois, ao afetar sua integridade corporal, compromete o senso de segurança, o estado psíquico e emocional da parturiente, violando o direito de controle sobre o próprio corpo, que constitui, possivelmente, o fundamento mais importante da liberdade sexual e reprodutiva.

Muitas pesquisadas relataram que sua sexualidade foi atingida porque elas sentiram dor nas relações sexuais (dispaurenia), e algumas mostraram uma certa irritação quando reconheceram o desrespeito à sua integridade corporal:

Só consegui ter relação sexual depois de dois meses, que tentei, pois doía tanto o local que foi muito ruim.(E5)

Única seqüela: dispaurenia por mais de um ano, devida à maldita episiotomia não autorizada.(E1)

0 retorno às atividades sexuais varia em um tempo que é singular para cada mulher. É fato que o desejo e a disposição para o retorno das relações sexuais variam muito entre as mulheres na dependência de sua libido, da cicatrização das incisões e/ou lacerações perineais e do grau de atrofia vaginal secundária à amamentação ${ }^{21}$.

Entretanto, quando é realizada a episiotomia, a idéia difundida de que a atividade sexual pode ser reiniciada logo no pós-parto, sempre que o períneo estiver adequado e quando o sangramento diminuir ${ }^{21}$, é altamente questionável, pois evidenciamos que para algumas mulheres o períneo não retornou ao estado de adequado nem mesmo depois de um ano de pós-parto.

Outras mulheres, além de apresentarem dificuldades para terem relações sexuais porque sentiam incômodo, também apresentaram a sensação de que não foram suturadas e que a ferida ainda estava aberta:

... tive mais dificuldade para ter relação... e me sentia arranhando, ardia, me incomodava. Parecia que o corte ainda estava aberto.(E2)

Nas duas imaginava se estavam me deixando toda larga e que ia ficar feio, ou não ia ficar bem costurado, já pensou ficar com ela toda torta... (E5)
Outra repercussão da episiotomia na sexualidade das mulheres que foi muito marcante diz respeito ao constrangimento causado em sua relação com o parceiro:

[...] com o tempo foi ficando aquela carnezinha [no local da episiotomia], pra fora, e toda vez ele notava e eu ia ficando constrangida com aquela situação.(E4)

Este constrangimento alterou a intimidade na relação sexual do casal:

[...], já não tinha a mesma facilidade de ficar nua para o meu marido, de ter relações normais com ele. Porque toda vez se tocava no assunto e eu ficava constrangida.(E4)

Chegou ao ponto de a mulher evitar as relações genitais, o que provavelmente foi um determinante a mais para a separação do casal:

Chegou um tempo que eu comecei a evitar a ter relação porque eu tinha vergonha daquilo. [...] Com mais ou menos um ano, [após a episiotomia], as coisas começaram a complicar e houve a separação [do marido], na verdade muitas coisas implicaram, mas mexeu tanto com o meu psicológico, que ficava um pouco complicado. (E4)

Por fim, existe em nossa sociedade a idéia da valorização do prazer como um direito do indivíduo e do casal ${ }^{2}$. Por isto mesmo, o sexo passou a ser um componente de importância crescente na determinação de nosso bem-estar físico-social, e não pode mais ser considerado somente para a reprodução; daí a necessidade de reflexão sobre as possíveis conseqüências que um procedimento como a episiotomia, por vezes usada rotineira e indiscriminadamente, pode acarretar na vida e na saúde das mulheres e dos casais.

Neste sentido, salientamos que, em função de a episiotomia estar associada a diversas complicações, tanto físicas quanto psicológicas, devemos encorajar o uso das tecnologias não invasivas de cuidado e as práticas alternativas que favorecem a redução da necessidade de realização deste procedimento ${ }^{22}$.

\section{CONSIDERAÇÕES FINAIS}

Este estudo contribuiu para que este procedimento seja cada vez mais questionado pelos profissionais em geral e os da enfermagem e reforça a idéia de que ele deve ser utilizado com muita prudência ou substituído definitivamente.

Através da análise dos depoimentos, evidenciamos as sensações vivenciadas pelas mulheres durante a realização da episiotomia e analisamos as repercussões deste procedimento sobre sua sexualidade.

Este estudo nos mostra que a episiotomia representa uma violação dos direitos sexuais e reprodutivos da mulher, assim como uma violência de gênero. Assim sendo, recomendamos que o cuidado das enfermeiras esteja pautado no respeito ao princípio de que 0 parto é um evento fisiológico e sexual, do qual a mulher deve participar ativamente; que enfermeiras obstétricas apliquem novas tecnologias de cuidado, de caráter não invasivo, que substituam este procedimento. Por fim, que as escolas de enfermagem, ao invés de priorizar o ensino deste procedimento cirúrgico, desenvolvam novas tecnologias de cuidado e capacitem enfermeiras para que estas passem a realizar a proteção perineal como uma prática incorporada às habilidades da profissão. 


\section{Referências}

1. Corrêa S, Petchesky R. Direitos sexuais e reprodutivos na perspectiva feminista. São Paulo (SP): UNICAMP; 1993.

2. Cook RJ, et al. Saúde reprodutiva e direitos humanos: integrando medicina, ética e direito. Rio de Janeiro (RJ): CEPIA \& Oxford; 2004.

3. Chauí M. Repressão sexual: essa nova [des] conhecida. São Paulo (SP): Brasiliense; 1991.

4. Odent M. 0 camponês e a parteira: uma alternativa à industrialização da agricultura e do parto. Tradução de Sarah Bauley. São Paulo (SP): Ground; 2003.

5. Odent M. 0 renascimento do parto. Tradução de Roland B. Calheiros. Florianópolis(SC): Saint Germain; 2002.

6. Waldow VR, Meyer DE, Lopes MJM. Gênero e saúde. Porto Alegre (RS): Artes Médicas; 1996.

7. Bourdieu P. A dominação masculina. Tradução de Maria Helena Kühner. Rio de Janeiro (RJ): Bertrand Brasil; 1999.

8. Barsted LL, Hermann J. A mulher e os direitos civis: traduzindo a legislação com a perspectiva de gênero. Rio de Janeiro (RJ): CEPIA; 1999.

9. Barsted LL. Fronteiras simbólicas: gênero, corpo e sexualidade. In: Pitanguy J, Mesquita R. Gênero, corpo e enfermagem. Rio de Janeiro (RJ): CEPIA; 2002.

10. Tomasso $G$, et al. Debemos seguir haciendo la episiotomía en forma rutinaria? Rev Obstetr Ginecol 2002; 62 (2): 115-21.

11. Costa SM, et al. Episiotomia: o que há de verdade neste tradicional procedimento? Femina 2001maio; 29(4): 201-03.
12. Carter FB, Wolber PGH. Episiotomy. In: Sciarra JJ, Gerbie AB. Gynecology and Obstetrics. Philadelphia(USA): Hagertown:Harper \&Row;1980.

13. Diniz CSG. Entre a técnica e os direitos humanos: possibilidades e limites da humanização da assistência ao parto [tese de doutorado].São Paulo (SP): Faculdade de Medicina / USP; 2001.

14. Mouta RJO, Morais FRC, Melo SB. Episiotomia e sexualidade: um olhar a partir da vivência feminina [monografia de pós- graduação em Enfermagem Obstétrica]. Rio de Janeiro (RJ): Escola de Enfermagem Raquel Hadock Lobo /UERJ; 2006.

15. Minayo MCS. Pesquisa social: teoria, método e criatividade. $16^{\mathrm{a}}$ ed. Petrópolis (RJ): Vozes; 2000.

16. Leopardi MT. Metodologia da pesquisa na saúde. Florianópolis (SC): Palloti; 2002.

17. Bardin L. Análise de conteúdo. Lisboa: Ed 70; 1977.

18. Ministério da Saúde (BR). Conselho Nacional de Saúde. Diretrizes e normas regulamentadoras de pesquisas envolvendo seres humanos. Resolução CNS n 196, de 10 de outubro de 1996. Inf Epidemiol SUS 1996; 5 (2 supl 3): 13-41.

19. Progianti JM, Penna LHG, Christoffel M. Parto e nascimento: reflexões de enfermeiras obstétricas. Rev Enferm Atual 2004 mar/abr: 23-26.

20. Zveiter M, Progianti JM, Vargens OMC. 0 trauma no parto e nascimento sob a lente da enfermagem obstétrica. Pulsional: rev psic 2005; 18:87-92.

21. Reany K, White SE. Obstetrícia: gestações normais e patológicas. Rio de Janeiro (RJ): Guanabara Koogan; 1999.

22. Progianti JM, Vargens OMC, Porfírio AB, Lorenzoni DP. A preservação perineal como prática de enfermeiras obstétricas. Esc Anna Nery Rev Enferm 2006 ago; 10(2): 266-72. 